\title{
Optimization of a Thermoelectric Cooling System with Peltier Effect
}

\author{
Louis Okotaka Ebale ${ }^{1,}$, , Landry Jean Pierre Gomat ${ }^{1}$, Nzonzolo ${ }^{2}$, Marc Romaric Mavoungou ${ }^{1}$, \\ Feldha Kibongani ${ }^{1}$ \\ ${ }^{1}$ Laboratoire de Mécanique, Energétique et Ingénierie, Ecole Nationale Supérieure Polytechnique, Université Marien Ngouabi, Brazzaville, \\ Congo \\ ${ }^{2}$ Laboratoire Genie Electrique et Electronique, Ecole Nationale Supérieure Polytechnique, Université Marien Ngouabi, Brazzaville, Congo
}

\author{
Email address: \\ dajlouis@yahoo.fr (L. O. Ebale) \\ ${ }^{*}$ Corresponding author
}

\section{To cite this article:}

Louis Okotaka Ebale, Landry Jean Pierre Gomat, Nzonzolo, Marc Romaric Mavoungou, Feldha Kibongani. Optimization of a Thermoelectric Cooling System with Peltier Effect. American Journal of Energy Engineering. Vol. 7, No. 3, 2019, pp. 55-63. doi: $10.11648 /$ j.ajee.20190703.11

Received: September 25, 2019; Accepted: October 8, 2019; Published: October 20, 2019

\begin{abstract}
The use of the Peltier effect for the cooling of a cooler powered by photovoltaic energy is a solution for the conservation of foodstuffs or pharmaceuticals when conditions as well geographical and climatic become difficult. Only a problem often arises with the choice of the supply current. Indeed, a choice of the supply current too low will produce less cold while a choice of too much supply current (very close to the maximum value indicated by the manufacturer of the module) will produce more cold, but the module will work in saturation, which will reduce its life. This article proposes to present the possibility of optimizing a thermoelectric refrigeration installation. In particular: by improving the performances of the installation, by maximizing the coefficient of performance and the cooling capacity as a function of the power supply current of the Peltier effect module (of the TEC1-12706 type). Thus, to solve this problem, we propose an optimization of the thermoelectric installation while passing by the method of the derivatives which will make it possible to find this optimal current. This optimal current will be average current corresponding to the performance coefficient and the current for which the refrigeration power becomes maximum.
\end{abstract}

Keywords: Thermoelectric Cooling, Thermoelectric Modules, Peltier, Seebeck, Optimization, Coefficient of Performance

\section{Introduction}

In order to satisfy the daily consumption, one is obliged to store consumables while maintaining a good quality. The cold does not improve the food, it keeps them in the state they are when they are placed in a refrigerator. Storage should be done at a given temperature and relative humidity. These conditions vary with the product. Since the shelf life is limited, refrigeration slows the vital phenomena of living tissues, such as fruits and vegetables, and dead tissues by slowing down biochemical metabolism, thus guaranteeing vitamins, hormones and enzymes. It also slows microbial evolution and consequences such as putrefaction. A commodity such as meat, for example, to be stored should be placed in an environment between $0^{\circ} \mathrm{C}$ and $4^{\circ} \mathrm{C}$ This temperature does not exist in tropical countries. The use of the Peltier effect for the cooling of a cooler powered by photovoltaic energy is a solution for the conservation of foodstuffs or pharmaceuticals when conditions as well geographical and climatic become difficult image (1). More than 170 years ago, Jean-Charles Peltier discovered a curious phenomenon: when an electric current crosses two drivers of different natures, one cools while the other warms (at the level of their respective junction). A little earlier, in 1821, Thomas Seebeck put an opposite phenomenon: indeed when two different conducting materials are close to each other, we obtain an electric current (admittedly weak) if the two junctions are brought to different temperatures $[1,2,3,13,16]$. Lord Kelvin later confirmed that the two discoveries were related to the same phenomenon, today called the thermoelectric effect $[4,5]$. A thermoelectric Peltier refrigeration system is an installation that uses Peltier effect modules that operate in refrigeration. Figures 2 and 3. Only a problem often arises with the choice of the 
supply current. Indeed, a choice of the supply current too low will produce less cold while a choice of too much supply current (very close to the maximum value indicated by the manufacturer of the module) will produce more cold, but the module will work in saturation, which will reduce its life. Thus, a choice of the optimal current is important and reassuring. The optimization of the real system will consist in separately maximizing the coefficient of performance $\varepsilon_{\mathrm{f}}$ and the cooling capacity of the installation $\dot{Q}_{0}$. Indeed, the voltage $U_{o p t}$ which gives the value of the maximum coefficient of performance is obtained by posing: $\frac{d \varepsilon_{f}}{d U}=0$; The result of this equation gives us the expression allowing to determine the optimal current corresponding to the maximum coefficient of performance by the relation: $I_{1}^{\text {opt }}=\frac{U_{\text {opt }}}{R} ; \mathrm{R}$ : being the electrical resistance of the thermoelectric couple. The optimum value of the current for which the cooling capacity becomes maximum is obtained by the relation: $\frac{\mathrm{dQ}_{0}}{\mathrm{dI}}=0$. The result of this equation gives us the expression to calculate the optimal current: $I_{2}^{o p t}=\frac{\alpha T_{0}}{R}$. The current $I_{1}^{\text {opt }}$ allows the module to consume a minimum electrical power and the current $I_{2}^{o p t}$ provides the module with maximum electrical power. The feed current $I^{o p t}$ will be chosen in the interval $\left[I_{1}^{o p t} ; I_{2}^{o p t}[[6]\right.$. The eclectic schematic diagram of the installation is shown in Figure 4. We will take as a precaution the average value:

$$
\mathrm{I}^{\mathrm{opt}}=\frac{\mathrm{I}_{1}^{\mathrm{opt}}+\mathrm{I}_{2}^{\mathrm{opt}}}{2}
$$

\section{Material and Method}

\subsection{Materials}

Figure 1 shows a thermoelectric micro-fridge (cooler), having a type Bismuth tellurium type TEC1-12706 module Figure $2[7,8]$ whose characteristics are given in Table 1. It is composed of a fan which extracts the hot air released by the outdoor radiator and an indoor fan that convects cold air into the cooler Figure 3.

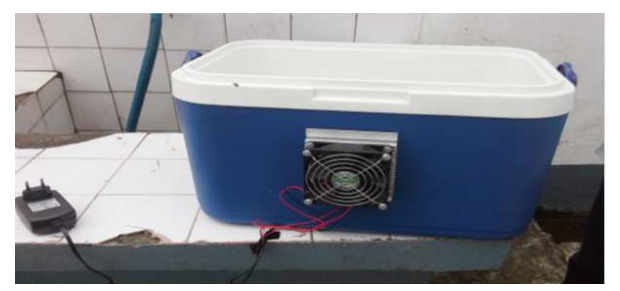

Figure 1. Thermoelectric micro-fridge (cooler).

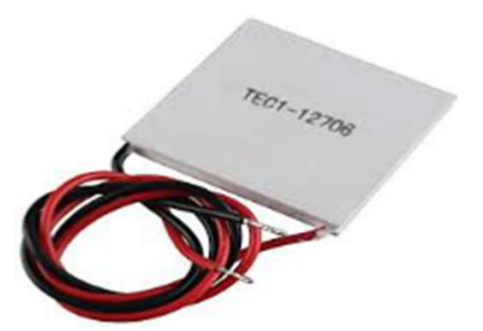

Figure 2. TEC1-12706 Bismuth tellurium type module.

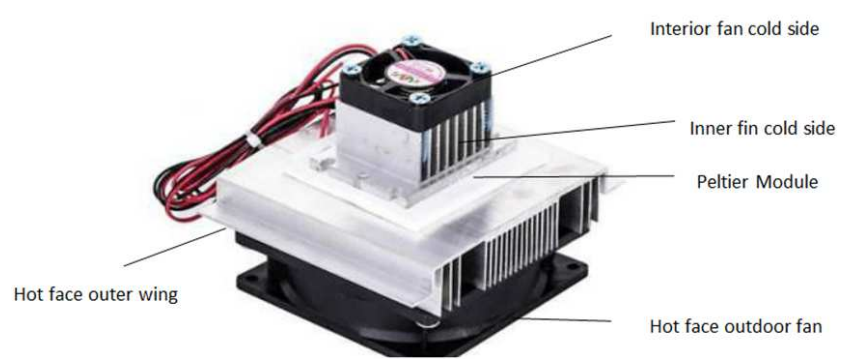

Figure 3. Thermoelectric installation composed of Peltier module.

Table 1. Initial technical characteristics of the installation.

\begin{tabular}{ll}
\hline Quantities & Values \\
\hline$T_{a}:$ Room temperature & $300 \mathrm{~K}$ \\
$T_{0}:$ Temperature reached by the cold junction & $263 \mathrm{~K}$ \\
$\boldsymbol{\alpha}:$ Thermoelectric power & $200 \boldsymbol{\mu} \mathrm{V} / \mathrm{K}$ \\
$\mathrm{N}:$ Number of thermoelectric couples & 127 \\
$Z:$ Characteristic size of the material & $3 \times 10^{-3} \mathrm{~K}^{-1}$ \\
$\dot{Q}_{0}:$ Cooling capacity & $20 \mathrm{~W}$ \\
$\varepsilon_{f}:$ Coefficient of performance & 0,40 \\
U: Voltage & $12 \mathrm{~V}$ \\
$\rho:$ Electrical resistivity & $10^{-5} \Omega m$ \\
I: Current & $6 \mathrm{~A}$ \\
\hline
\end{tabular}

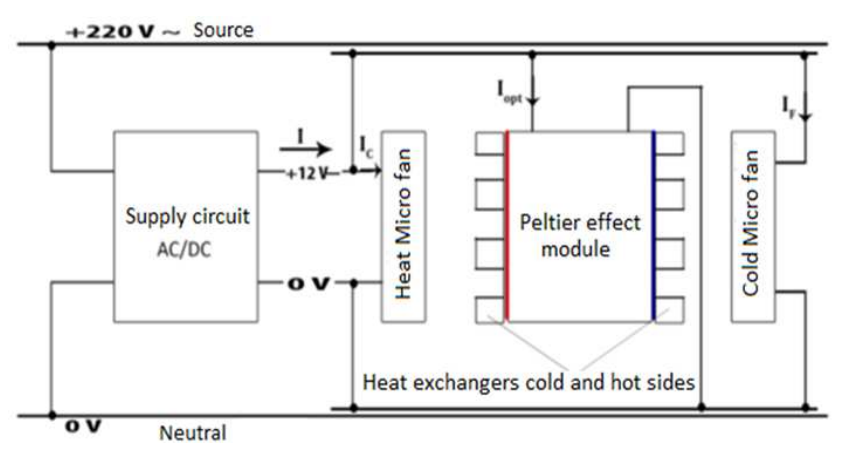

Figure 4. Block diagram of the assembly.

\subsection{Method}

The method is based on a power budget for a thermoelectric material qualified as a standard model [9, 15]. The main electrical quantity that will produce cold or heat is the supply current of the Peltier effect module. Subsequently, mathematical models have been developed that combine the standard heat transfer equations for thermoelectricity that take into account the Seebeck and Joule effects. This method consists in separately maximizing the coefficient of performance and the cooling capacity of the installation. It allows, by using a DC voltage source $(U)$, to study the transient temperature setting of the assembly, by establishing the relation $\dot{Q}_{0}=\mathrm{f}$ $\left(\mathrm{U}, \mathrm{T}_{0}, \mathrm{~T}_{\mathrm{a}}\right.$ ), to determine the number of thermoelectric couples. of the module, the power supply device, the overall resistance of the heat exchangers and the surface of the module that will be needed [10]. The choice of the supply circuit must take into account the optimal intensity $\mathrm{I}_{\text {opt }}$. Figure 4 . In the figure 5 , it is presented the principle of operation of Peltier thermoelectric system. 


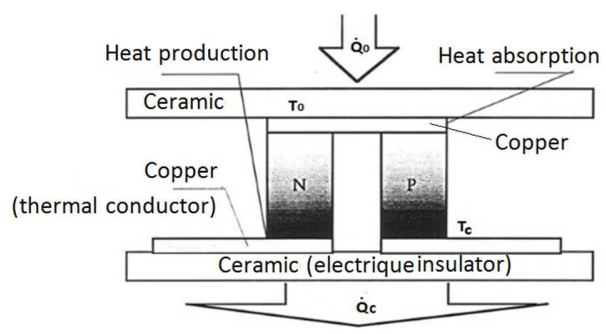

Figure 5. Peltier thermo-electric system.

1. Heat absorbed or evacued at welding points

On the welding points appears a warmth that is expressed through the relationship:

$$
Q_{p}=\pi . I . \tau(J)
$$

With:

$-\pi$ : Peltier coefficient $(\mathrm{V})$;

-I: Intensity of the module supply current (A);

$-\tau$ : Time in second (s).

2. Heat received as a result of thermal conduction

The material is a thermal conductor; the heat conveyed is expressed by:

$$
Q_{F}=\left(k_{1}+k_{2}\right)\left(T_{c}-T_{0}\right) \tau(\mathrm{J})
$$

With:

$$
k_{1}+k_{2}=k=\lambda \frac{S}{l}
$$

L: Length of the portion (m);

$\mathrm{k}$ : Thermal conductivity constant $\left(\mathrm{W} / \mathrm{m}^{2} \mathrm{~K}\right)$

$\lambda$ : Thermal conductibility of the portion $(\mathrm{W} / \mathrm{K})$;

S: Section $\left(\mathrm{m}^{2}\right)$

3. Heat $\mathrm{Q}_{\mathrm{J}}$ evacuated by half by Joule effect an half the middle

The heat gained by Joule effect and in the environment is expressed by:

$$
Q_{J}=\frac{1}{2}\left(R_{1}+R_{2}\right) I^{2} \tau(J)
$$
$(\Omega)$

With $\mathrm{R}_{1}+R_{2}=R=\rho \frac{l}{S}$ : Resistance of a thermocouple

$\rho$ : Electrical resistivity of the material. $(\Omega \mathrm{m})$

4. Heat $Q_{0}$ taken by the thermoelement in the middle has cool:

In stationary operating regime, the $\operatorname{sum} Q_{0}, Q_{F}, Q_{J}$ of the three components is equal to the heat evacuated by Peltier effect, i.e.:

$$
Q_{p}=Q_{0}+Q_{F}+Q_{J}(\mathrm{~J})
$$

By replacing (1), (2), (3), (4) in (5) we have:

$$
\pi . I . \tau=Q_{0}+\left(k_{1}+k_{2}\right)\left(T_{c}-T_{0}\right) \tau+\frac{1}{2}\left(R_{1}+R_{2}\right) I^{2} \tau
$$

Depending on the time, we have:

$$
\dot{Q}_{0}=\frac{Q_{0}}{\tau}=\pi I-0,5\left(R_{1}+R_{2}\right) I^{2}-\left(k_{1}+k_{2}\right) \Delta T
$$

Considering: $T_{c}=T_{a}$

$-\mathrm{T}_{\mathrm{a}}$ : Ambient temperature $(\mathrm{K})$;

$-\mathrm{T}_{0}$ : Temperature of the cold side of the module $(\mathrm{K})$

$-\mathrm{T}_{\mathrm{C} \text { : }}$ Temperature of the hot side of the module $(\mathrm{K})$

$-\mathrm{U}=R I$ : Electric power voltage $(\mathrm{V})$;

$-\Delta \mathrm{T}=T_{a}-T_{0}:$ Temperature difference between the ambient and the cold side of the module $(\mathrm{K})$;

$-\mathrm{k}_{1}, \mathrm{k}_{2}$ : Thermal conductivity of the tow materials $\left(\mathrm{W} / \mathrm{m}^{2} \mathrm{~K}\right)$

Between the Peltier coefficient and the Seebeck coefficient, there is relationship:

$$
\pi=\left(\alpha_{1}-\alpha_{2}\right) T=\alpha T
$$

- $\alpha_{1}, \alpha_{2}$ : Seebeck thermoelectric coefficient of the tow materials $(\mathrm{V} / \mathrm{K})$;

We can express the heat absorbed $\mathrm{Q}_{0}$ depending on the $\mathrm{U}$ tension by relationship:

$$
\dot{Q}_{0}=\frac{Q_{0}}{\tau}=\alpha T_{0} I-0,5 R I^{2}-k \Delta T=\left(\alpha T_{0}-0,5 U-k \frac{R}{U} \Delta T\right) I
$$

5. The electric power supply Pe of the module.

This power is composed of the following terms:

a. The term $\mathrm{P}_{\mathrm{t}}$ represents the component to overcome thermo-electromotor voltage

$$
\mathrm{P}_{\mathrm{t}}=\mathrm{EI}=\left(\alpha_{1}-\alpha_{2}\right)\left(\mathrm{T}_{\mathrm{a}}-\mathrm{T}_{0}\right) \mathrm{I}=\left(\alpha_{1}-\alpha_{2}\right) \Delta \mathrm{T} . \mathrm{I}(W)
$$

b. The term $\mathrm{P}_{\mathrm{j}}$ represents the component of the electrocaloric effect

$$
\mathrm{P}_{\mathrm{J}}=\left(\mathrm{R}_{1}+\mathrm{R}_{2}\right) \mathrm{I}^{2}(W)
$$

It result in the total electrical power $\mathrm{P}_{\mathrm{e}}$ expressed by the relationship:

$$
P_{e}=\mathrm{P}_{\mathrm{t}}+\mathrm{P}_{\mathrm{J}}=[\mathrm{RI}+\alpha \Delta \mathrm{T}] \mathrm{I}=\left[\mathrm{U}+\alpha\left(\mathrm{T}_{\mathrm{a}}-\mathrm{T}_{0}\right)\right] \mathrm{I}(\mathrm{W})
$$

6. Maximum coefficient of performance

The maximum value of the coefficient of performance noted $\varepsilon_{\mathrm{f}}$ depends mainly on the optimum value of the current or the supply voltage and the parameters $\alpha$ and $\mathrm{Z}$ of the materials used for the semiconductors. Its expression according to the current or the tension is:

$$
\mathcal{E} f=\frac{\dot{Q}_{0}}{P_{e}}=\frac{\alpha T_{0}-0,5 U-k \frac{R}{U} \Delta T}{\mathrm{U}+\alpha\left(\mathrm{T}_{\mathrm{a}}-\mathrm{T}_{0}\right)}
$$

The optimal voltage $U_{\text {opt }}$ which gives the maximum value of the coefficient of performance is defined such as:

$$
\frac{d \varepsilon_{f}}{d U}=0
$$

We obtain the second degree equation of $U=U$ Upt, the optimum tension on the form:

$$
\mathrm{kR} \alpha \mathrm{Y}^{2}+2 \mathrm{kRY}-0,5 \alpha \Delta \mathrm{T}-\alpha \mathrm{T}_{0}=0
$$

where 


$$
Y=\frac{\Delta T}{U_{o p t}}
$$

It comes:

$$
\begin{aligned}
& Y_{1}=\frac{-k R-\sqrt{(k R)^{2}+k R \alpha^{2}\left(T_{0}+\frac{\Delta T}{2}\right)}}{k R \alpha} \\
& Y_{2}=\frac{-k R+\sqrt{(k R)^{2}+k R \alpha^{2}\left(T_{0}+\frac{\Delta T}{2}\right)}}{k R \alpha}
\end{aligned}
$$

The supply voltage being positive, we will therefore consider the value of $Y_{2}$

Taking into account equation (16), we obtain the optimum voltage followed:

$$
U_{\text {opt }}=\frac{\alpha \Delta T\left[1+\sqrt{1+\frac{\alpha^{2}}{k R}\left(T_{0}+\frac{\Delta T}{2}\right)}\right]}{\frac{\alpha^{2}}{k R}\left(T_{0}+\frac{\Delta T}{2}\right)}
$$

Denoting by:

$$
\begin{gathered}
Z=\frac{\alpha^{2}}{K R}(\text { characteristic size of the material }) \\
r=\frac{\alpha^{2}}{k R}\left(T_{0}+\frac{\Delta T}{2}\right)=Z\left(T_{0}+\frac{\Delta T}{2}\right) \\
M=\sqrt{1+r}
\end{gathered}
$$

The expression of the current corresponding to the maximum coefficient of performance can be written:

$$
I_{1}^{o p t}=\frac{V_{o p t}}{R}=\frac{\alpha \Delta T}{M-1} \times \frac{1}{R}
$$

and the the average temperature as:

$$
T_{m o y}=\frac{T_{0}+T_{\alpha}}{2}=T_{0}+\frac{\Delta T}{2}
$$

By reducing the optimal tension in the expression of the coefficient of performance, we obtain:

$$
\varepsilon_{\mathrm{f}}^{\max }=\frac{\mathrm{T}_{0}}{\Delta \mathrm{T}} \mathrm{X} \frac{1-0,5 \frac{\mathrm{T}_{0}}{\Delta \mathrm{T}} \times \frac{1}{\mathrm{M}-1}-\frac{\mathrm{T}_{\mathrm{moy}}}{\mathrm{T}_{0}} \times \frac{1}{\mathrm{M}+1}}{1+\frac{1}{\mathrm{M}-1}}
$$

In the expression obtained, we notice the presence of the factor $\frac{T_{0}}{\Delta T}$ which represents the coefficient of performance of the reference Carnot cycle, delimited by the temperatures $T_{0}$ and $T_{a}$.

$$
\varepsilon_{c}=\frac{T_{0}}{\Delta T}=\frac{T_{0}}{T_{a}-T_{0}}
$$

Then (25) becomes:

$$
\varepsilon_{f}^{\max }=\varepsilon_{c}\left[1-\frac{1}{M}\left(1+\frac{0,5}{\varepsilon_{c}}\right)-\frac{T_{m o y}}{T_{0}} \times \frac{1}{M} \times \frac{M-1}{M+1}\right]
$$

7. Optimum voltage of a thermocouple

The optimum voltage for a thermoelectric torque is defined by:

$$
U_{1}^{o p t}=\frac{\alpha \times \Delta T}{M-1}(V)
$$

8. Electrical resistance of a thermocouple.

According to equation (23) this resistance is defined as follows:

$$
R=\frac{\alpha \Delta T}{I_{1}^{o p t} \times(M-1)}(' \Omega)
$$

9. Total electrical resistance of the module battery It is calculated by:

$$
R_{t}=\frac{U}{I_{1}^{o p t}}(' \Omega)
$$

10. Average temperature reached by the module It is determined by:

$$
T_{\text {moy }}=\frac{T_{0}+T_{a}}{2}=T_{0}+\frac{\Delta T}{2}(K)
$$

11. Maximum cooling capacity of a thermoelectric couple

The maximum cooling capacity of a thermocouple is obtained under optimum conditions where the intensity of the electric current is optimal. By neglecting the heat transmitted by conduction towards the cold welds $(Q F=0)$, and considering the case where $\mathrm{k}=0$, the equation (1) of the cooling capacity of the module is written:

$$
\dot{Q}_{0}=\alpha T_{0} I-\frac{R I^{2}}{2}=\dot{Q}_{p}-\dot{Q}_{j}
$$

With: $\dot{\mathrm{Q}}_{\mathrm{p}}=\alpha \mathrm{T}_{0} \mathrm{I}$ (Term related to the Peltier effect, cold side), $\dot{Q}_{\mathrm{J}}=\frac{\mathrm{RI}^{2}}{2}$ (Term related to the Joule effect). The optimum value of the current for which $\dot{\mathrm{Q}}_{0}$ becomes maximal, is obtained by the relation:

$$
\frac{d \dot{Q}_{0}}{d I}=0
$$

We have

$$
\frac{d \dot{Q}_{0}}{d I}=\alpha T_{0}-R I_{o p t}
$$

Let the optimum current for which $\dot{Q}_{0}$ be maximal:

$$
I_{\text {opt }}=\frac{\alpha T_{0}}{R}
$$

With $\mathrm{R}=\mathrm{R}_{1}$.

Then (40) becomes:

$$
\dot{Q}_{01}^{\max }=\frac{\left(\alpha T_{0}\right)^{2}}{R}-\frac{\left(\alpha T_{0}\right)^{2}}{2 R}
$$

Finally:

$$
\dot{Q}_{01}^{\max }=\frac{\alpha^{2} T_{0}^{2}}{2 R}(W)
$$

12. Number of thermoelectric couples under optimal conditions

The number $\mathrm{N}_{\mathrm{opt}}$ of thermoelectric couples in optimal conditions is defined by:

$$
N_{o p t}=\frac{U}{U_{1}^{o p t}}
$$

13. Maximum cooling capacity of the installation 
Taking into account the number of thermoelectric couples housed in the soles or blocks of the module, this power is obtained by the relation (39):

$$
\dot{Q}_{0}^{\max }=N_{\text {opt }} \times \dot{Q}_{01}^{\max }(\mathrm{W})
$$

14. Intensity of the current for which $\dot{Q}_{0}$ is maximum The optimal current under the conditions of $\dot{Q}_{0}^{\max }$ :

$$
I_{2}^{o p t}=\frac{\alpha T_{0}}{R}(\mathrm{~A})
$$

15. Maximum temperature difference

Taking into that $\dot{Q}_{0}=0$ and $\varepsilon f=0$, we obtain the maximum temperature difference such as:

$$
\Delta T_{\text {max }}=0,5 \times Z \times T_{0}^{2}
$$

The minimum temperature of the cold junction under those maximum conditions is defined by:

$$
T_{0}^{\text {mini }}=\frac{\sqrt{1+2 Z T_{a}}-1}{Z}
$$

16. Minimum electrical power required by the module.

Under the optimization conditions, the electrical power during operation of a Peltier thermoelectric module is not obtained directly by the product $\mathrm{U} \times \mathrm{I}$, it can be deduced by the relation:

$$
P_{e}=\frac{\dot{Q}_{0}}{\varepsilon_{f}}
$$

In this relation (43), the power is minimal for $\varepsilon_{f}=\varepsilon \max$ It is defined by the relation:

$$
P_{\min }=\frac{\dot{Q}_{0}}{\varepsilon_{f}^{\max }}
$$

17. Intensity of the current for which $\varepsilon f$ is maximum

The intensity of the current which gives the maximum of the cooling efficiency is:

$$
I_{1}^{O P T}=\frac{P_{\min }}{U}
$$

18. Thermal power discharged by the module

The thermal power discharged by the module is defined by the following relation (46):

a) Coefficient of performance of the Carnot cycle

$$
\dot{Q}_{c}=\dot{Q}_{0}+P_{\text {min }}
$$

19. Maximum electrical power consumed by the module

The maximum electrical power required by the module depends on the optimum current value $I_{2}^{o p t}$ corresponding to the maximum cooling capacity. It is determined by:

$$
P_{\text {max }}=N_{\text {opt }}\left[R *\left(I_{2}^{o p t}\right)+\alpha \Delta T\right] I_{2}^{o p t}
$$

20. Intensity of the current of the module power supply.

There are two possible choices of supply current, the first choice is the optimal value $I_{1}^{\text {opt }}$ relative to the maximum coefficient of performance. This current will allow the module to consume minimal electrical power. The second choice is to attribute to the feed current the value of current $I_{2}^{\text {opt }}$ corresponding to the maximum cooling capacity. This current will provide the module with maximum electrical power. For greater security, the optimum current Iopt supply of the module will be chosen in the interval $\left[I_{1}^{o p t} ; I_{2}^{o p t}[\right.$. We will take as a precaution the average value of currents $I_{1}^{o p t}$ et $I_{2}^{o p t}$ or:

$$
I_{o p t}=\frac{I_{1}^{o p t}+I_{2}^{o p t}}{2}
$$

\section{Discussion of Results}

On the graphs, the intensity of the supply current of the module has been represented on the abscissa. The simulation was done at room temperature $\mathrm{Ta}=300 \mathrm{~K}$. For each variation of the supply current of the module, it is noted that the coefficient of performance of the reference Carnot cycle remains constant Figure 6. While the real coefficient of performance of the minimum electrical power required by the module will be calculated with respect to this first optimal current Figure 7. The minimum electrical power required per module will be calculed in relation to this first optimal current. Figures 8 and 9 show that the electrical and thermal power gradually vary according to the supply current. The cooling power has an arrow which shows the existence of a maximum corresponding to a second optimum value of the module supply current. The maximum value of the electrical power demanded by the module will be calculated as a function of this second optimal current.

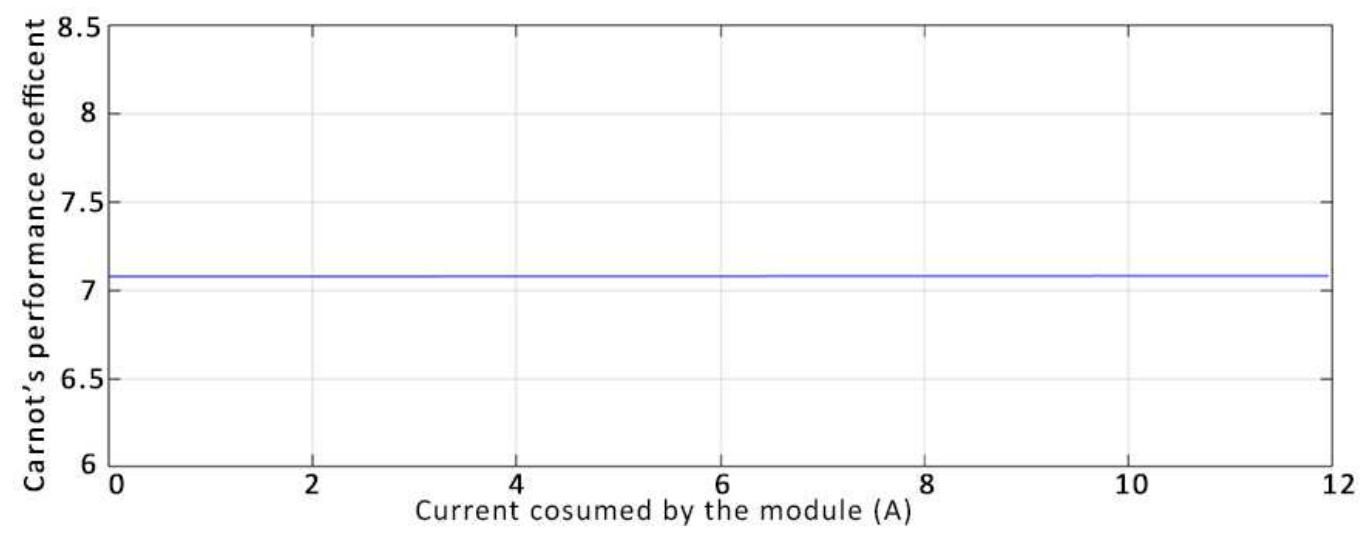

Figure 6. Variation in Carnot coefficient of performance versus current $I$. 
b) Coefficient of performance of the installation

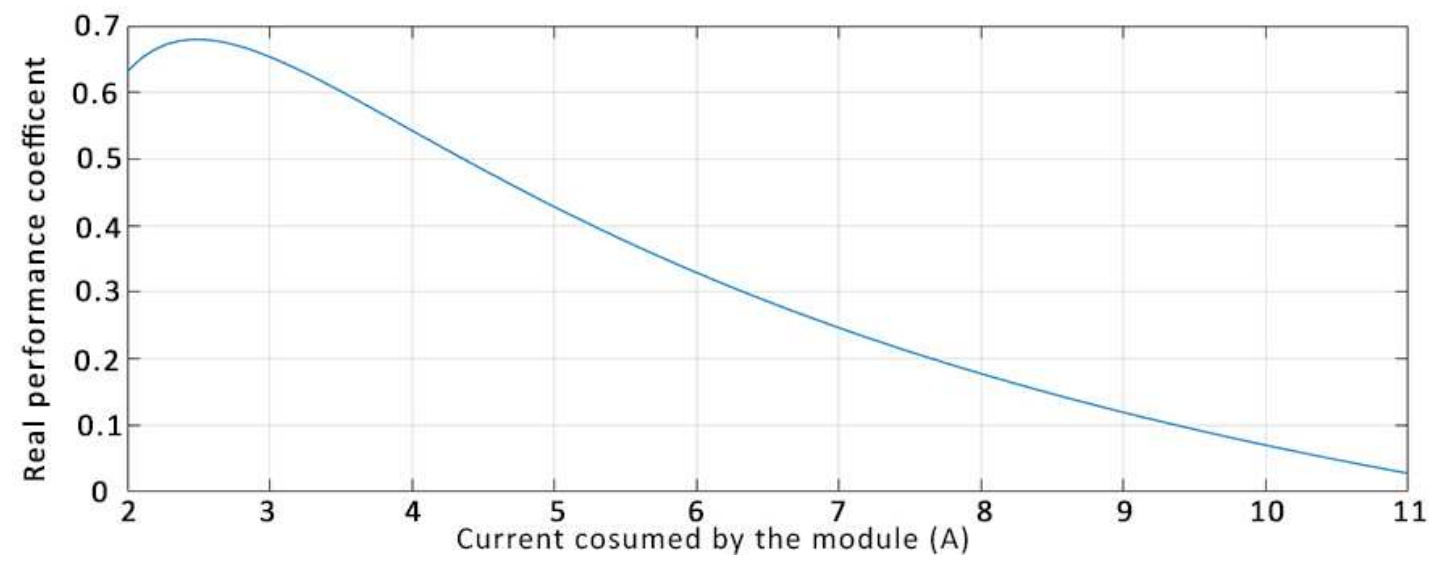

Figure 7. Variation of the performance coefficient of the installation according to current $I$.

c) Electrical power of installation

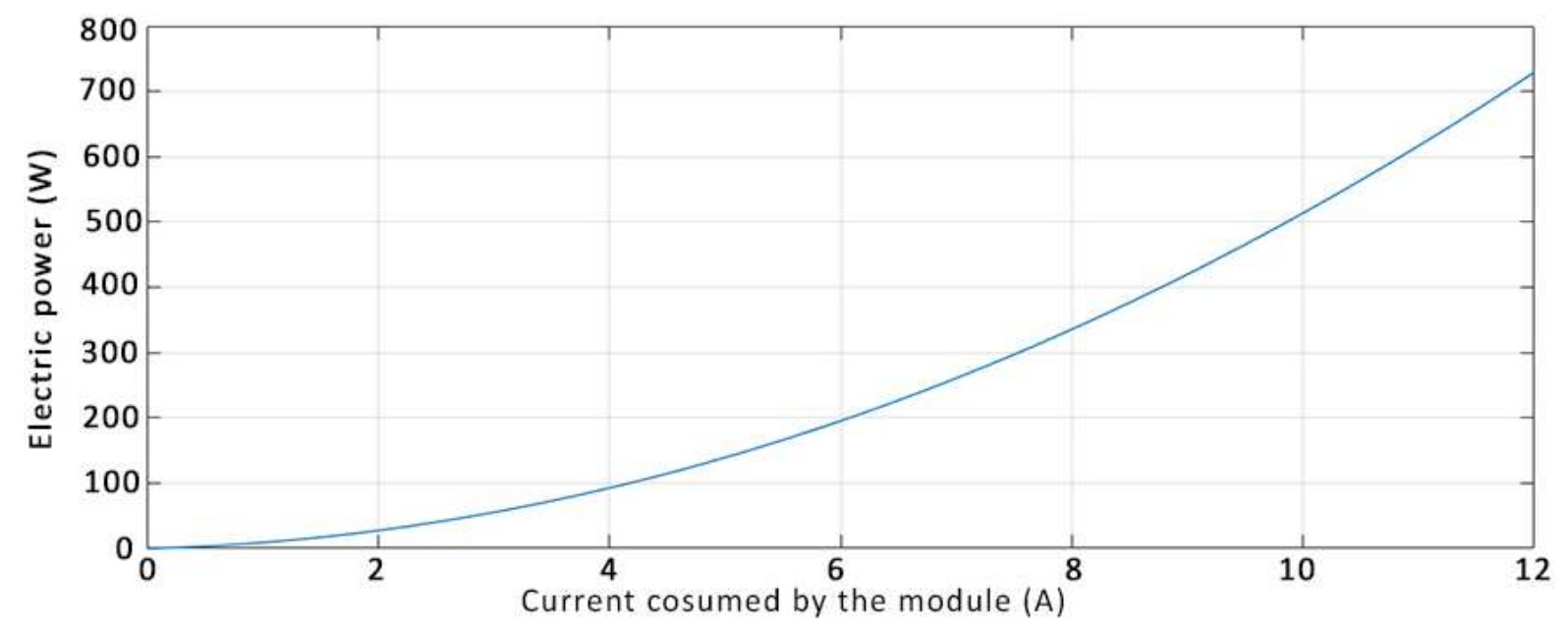

Figure 8. Variation of the electrical power of the installation according to the current $I$.

d) Heat flow to be evacuated by the module

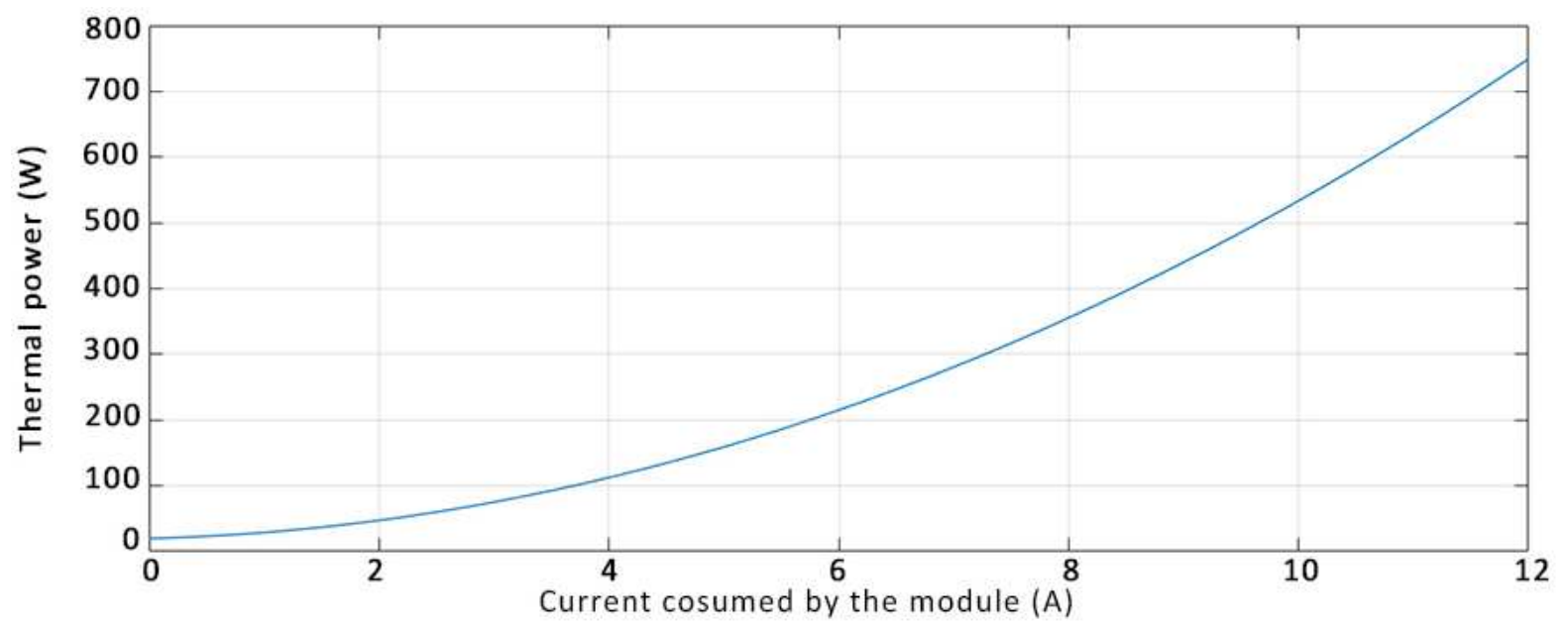

Figure 9. Heat flow variation versus current I.

e) Cooling capacity of the installation 


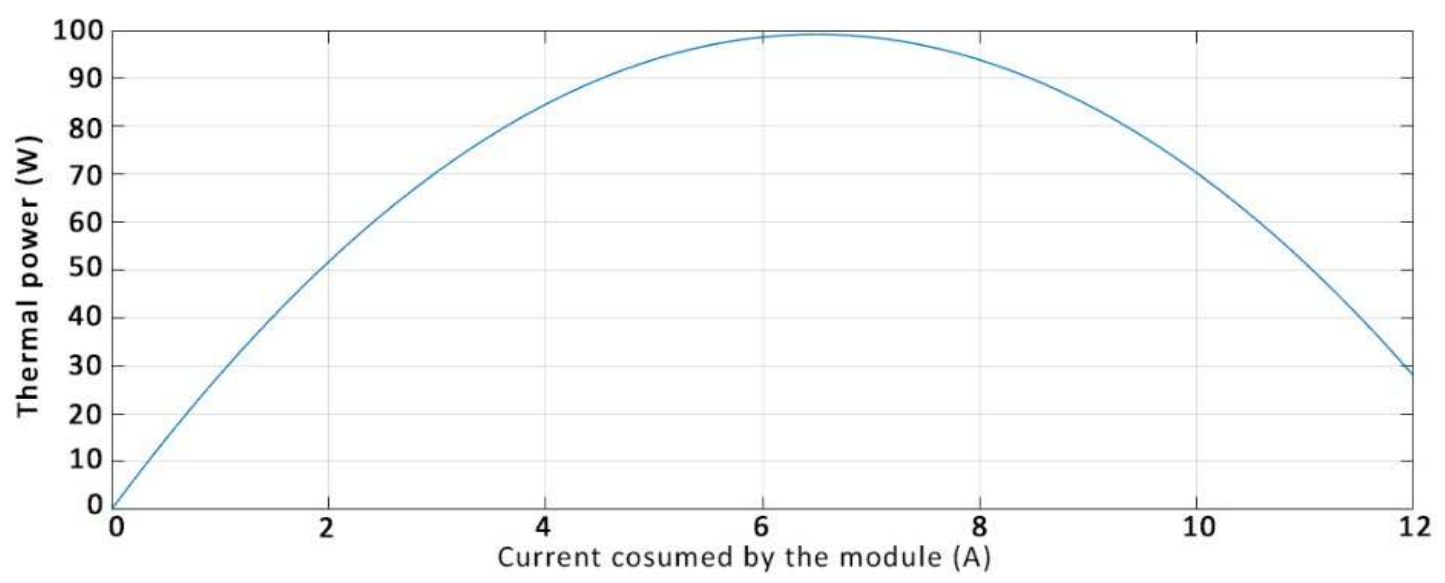

Figure 10. Variation of the cooling capacity of the plant as a function of the current I.

On the other hand, the observations made on the graph of the refrigerating power Figure 10, are such that:

At the initial moment, $\mathrm{I}=0 \mathrm{~A}$, which gives zero cooling capacity, corresponds to the de-energized state of the module.

When $I \in] 0 ; \mathrm{I}_{\text {opt }}$ [, The temperature of the cold junction of the module decreases progressively until it reaches the calibration value or its minimum value as a function of the voltage and the supply current. The cooling capacity follows the same progressive rate of change in the increasing direction, since it is related to both the temperature of the cold junction and the supply current of the module. Which is obvious. When the current varies, the cooling capacity also varies.

At $\mathrm{I}=\mathrm{I}_{\mathrm{opt}}$, the optimum operating point $\left(\mathrm{I}_{\mathrm{opt}} \dot{Q}_{0}{ }^{\max }\right)$, is the point where the steady state is established between the cooling effect of Peltier and the heating effect of Joule. The maximum cooling capacity is provided on the cold side and the Joule effect tends to be concealed by the cooling effect of
Peltier. Under these conditions, the flow on the cold side becomes twice the heat flux released by the Joule effect.

For $\mathrm{I} \in] I_{o p t} ;+\infty$ [, the supply current exceeds the optimal current gradually, the power released by Joule effect gradually increases and a large amount of heat is transmitted gradually by conduction to the cold junction, which reflects the fact that the temperature cold goes back up to tend towards the temperature of the hot welding. Hence the cooling capacity in turn also decreases gradually.

When $I \rightarrow I_{\infty}=2 \times \frac{\alpha T_{0}}{R}$, the heating power released by the Joule effect reaches its extremes, the temperature of the cold part and the temperature of the hot part of the module vary until a maximum temperature difference is reached.. A second steady state is established between the cold side flow and the Joule effect heat flux. Under these conditions, the cooling capacity is canceled again.

Table 2. Digital application of the optimization of the thermoelectric micro-fridge.

\begin{tabular}{ll}
\hline Results obtained for the optimization & \\
\hline Mean temperature & $T_{\text {moy }}=281,5 \mathrm{~K}$ \\
Minimum cold temperature & $T_{0}^{\min }=224,4 \mathrm{~K}$ \\
Number of optimal thermoelectric couples & $N_{\text {opt }}=581$ couples \\
Maximum coefficient of performance of the module & $\varepsilon_{f}^{\max }=0,66$ \\
Minimum electrical power required & $P_{\min }=30,51 \mathrm{~W}$ \\
Thermal power to be evacuated by the module & $\dot{Q}_{c}=50,51 \mathrm{~W}$ \\
Intensity of the current corresponding to the maximum coefficient of performance & $I_{1}^{\text {opt }}=2,54 \mathrm{~A}$ \\
Resistance of a thermoelectric couple & $R=0,0081 \Omega$ \\
Maximum cooling capacity of a thermoelectric couple & $\dot{Q}_{01}^{\max }=0,1702 \mathrm{~W}$ \\
Total maximum cooling capacity of the installation & $\dot{Q}_{0}^{\max }=98,87 \mathrm{~W}$ \\
Optimum current intensity for cooling capacity $\dot{Q}_{0}^{\max }$ maximum & $I_{2}^{\text {opt }}=6,5 \mathrm{~A}$ \\
Maximum electrical power of the installation & $P_{\max }=225,55 \mathrm{~W}$ \\
Optimal current intensity & $I_{\text {opt }}=4,52 \mathrm{~A}$ \\
\hline
\end{tabular}

\section{Conclusion}

It goes without saying that we always try to obtain a better coefficient of refrigeration performance of an installation while keeping in mind that it can not exceed its theoretical maximum namely the coefficient of performance of Carnot. Due to the compact nature and easy implementation of the Peltier thermoelectric modules, it is necessary to go through an optimization of the main parameters to improve its performance. One of the objectives of this study was to propose the mathematical model of the Peltier effect, which makes it possible to optimize the coefficient of performance and the cooling capacity of the installation.

The optimization of the coefficient of performance and the cooling capacity made it possible to find a limit range of currents necessary for the choice of an optimal current making it possible to operate the module in the optimal conditions. The results of our study for an optimal operation of our installation have been given in Table 2. It can be seen 
that this coefficient of performance is much higher than that presented by the manufacturer:

$\varepsilon_{f}^{\max }=0,66>\varepsilon_{f}=0,40$, for an optimum intensity much lower than that prescribed by the manufacturer is: $I_{o p t}=$ $4,52 A<6 \mathrm{~A}$. Finally, to ensure optimum operation of the installation, the regulating system of this one will have to be programmed according to the optimal current.

\section{Nomenclature}

I: Intensity of the module supply current

$\mathrm{I}_{1}^{\text {opt }}$ : Optimum current intensity corresponding to the maximum coefficient of performance

$\mathrm{I}_{2}^{\text {opt }}$ : Optimum current intensity relative to the maximum cooling capacity

$\mathrm{I}_{\text {opt }}$ : Intensity of the optimal power supply of the module

$\mathrm{k}$ : Thermal conductivity constant

$\mathrm{N}$ : Number of thermoelectric couples

$\mathrm{N}_{\text {opt }}$ : Optimum number of thermoelectric couples

$\mathrm{P}_{\text {min }}$ : Minimum electrical power of the installation

$\mathrm{P}_{\text {max }}$ : Maximum electrical power of the installation

$\mathrm{P}_{e}$ : Electrical power of the installation

$\dot{Q}_{0}$ : Cooling capacity of the module

$\dot{Q}_{c}$ : Thermal power to be evacuated by the module

$\dot{Q}_{01}^{\max }$ : Maximum cooling capacity of a thermocouple

$\dot{Q}_{0}^{\max }$ : Maximum cooling capacity of the installation

$\dot{Q}_{p}$ : Cold side flux, related to Peltier effect

$\dot{Q}_{j}$ : Thermal flux, related to the Joule effect

$\mathrm{R}$ : Resistance of a thermocouple

$\mathrm{R}_{t}$ : Total electrical resistance of the module battery

$\mathrm{T}_{a}$ : Ambient temperature

$\mathrm{T}_{0}$ : Temperature of the cold side of the module

$\mathrm{T}_{\text {min }}$ : Temperature of the installation

$\mathrm{T}_{0}^{\mathrm{min}}$ : Minimum cold temperature of the installation

U: Peltier module power supply

$\mathrm{U}_{\text {opt }}$ : Optimum supply voltage of a thermocouple

$\alpha$ : Thermoelectric power or Seebeck coefficient

$\varepsilon^{f}$ : Coefficient of performance of the installation

$\varepsilon_{f}^{\max }$ : Maximum performance coefficient of the installation

$\Delta \mathrm{T}$ : Temperature difference between the ambient and the cold side of the module

$\Delta \mathrm{T}_{\text {max }}$ : Temperature difference between the ambient and the cold side of the module

$\rho$ : Electrical resistivity of the material.

\section{References}

[1] Luis David Palatiño López (2004). Caractérisation des propriétés thermoélectriques des composants en régime harmonique: Technique et Modélisation. Thèse de doctorat, Université de Bordeaux 1, Ecole Doctorale des Sciences Physiques et de l'Ingénieur.

[2] Véronique DA ROS (2008). Transport dans le composés tyhemoélectriques Skutterudites de type $\mathrm{R}_{x} \mathrm{CO}_{4-y} \mathrm{Ni}_{y} \mathrm{Sb}_{12}(\mathrm{R}$ $=N d, Y b$ et $I n$ ). Thèse de doctorat, Université de Lorraine, Institut National Polytechnique de Lorraine.
[3] Jean David GRENON (2016). Système de mesure des propriétés thermoélectriques appliqués au phosphore noire. Mémoire, Université de Montréal, Eole Polytechnique de Montréal.

[4] Jean Baptiste VANEY (2014). Contribution à l'étude des propriétés de vitrocéramiques et verres de chalcogénures semi-onducteurs. Thèse de doctorat, Université de Lorraine, Institut Jean Lamour (Nancy)-Institut Charles Gerhard (Montpelier).

[5] Renaud de la Taille-Pierre Courbier (1984). La physique amusante/Science et vie. Collection Savoir et Comprendre. 24 expériences réalisées par Science et vie-Pierron. Pages 6367.

[6] Pierre CHAPOUL, Christophe DOM, Paul GALLAIS, Kevin GUERINEAU, Jean Baptiste MOUSSARD (2008). Conversion de la chaleur en électricité: Etude du module thermoélectrique à effet Peltier. Rapport du projet de physique, Institut National des Sciences Appliquées de Rouen. Pages 2 .

[7] Robert OTEY et Barry MOSKOWITZ (2001). Thermoelectric coolers offer efficient solid-stade heat management options. oe magazine.

[8] J. G. STOCKHOLM (2002). Générateur thermoélectrique, Énergie potable: autonomie et intégration dans l'environnement humain. -Cachan-Journées électrotechniques du club EEA.

[9] Pr. Dr. Ing. Radcenco VSEVOLOD Sef Lucr. Ing. Porneală SAVA Asist. Ing. Alexandru DOBROVICESCU (1983). Processe in instalatii frigorice. EDITURA DIDACTICA PEDAGOGICĂ, BUCURESTI. Pages 359-365.

[10] Pierre CHAPOUL, Christophe DOM, Paul GALLAIS, Kevin GUERINEAU, Jean Baptiste MOUSSARD (2008). Conversion de la chaleur en électricité: Etude du module thermoélectrique à effet Peltier. Rapport du projet de physique, Institut National des Sciences Appliquées de Rouen. Pages 22-23.

[11] Camille FAVAREL (2014). Optimisation de générateurs thermoélectriques pour la production d'électricité. Thèse de doctorat, Université de Pau et des pays de L'Adour, École Doctorale des Sciences Exactes et de leurs Applications. Spécialité: Génie Électrique/Énergétique.

[12] Zhang HY, Mui YC, Tarin M. Analysis of thermoelectric cooler performance high power electronic packages. Appl Therm Eng (2010); 30: 561-8. http://dx.doi.org/10.1016/j.applthermaleng.2009.10.020.

[13] María Ibañez-Puy, Javier Bermejo-Busto, César MartínGómez, Marina Vidaurre-Arbizu, José Antonio SacristánFernández, Thermoelectric cooling heating unit performance under real conditions Applied Energy 200 (2017) 303-314. http://dx.doi.org/10.1016/j.apenergy.2017.05.020.

[14] Marco Nesarajah and and Georg Frey, Thermoelectric Power Generation: Peltier Element versus Thermoelectric Generator, 978-1-5090-3474-1/16/\$31.00 (2016) IEEE.

[15] Xiao Zhang, Li-Dong Zhao, Thermoelectric materials: energy conversion between heat and electricity, Journal of Materiomics (2015), doi: 10.1016/j.jmat.2015.01.001.

[16] Zeki Yilmazoglu, Experimental and numerical investigation of a prototype thermoelectric heating and cooling unit, Energy

and Buildings (2015), http://dx.doi.org/10.1016/j.enbuild.2015.12.046. 
[17] Hamidreza Najafi, Keith A. Woodbury, Optimization of a cooling system based on Peltier effect for photovoltaic cells, Solar $\quad$ Energy $91 \quad$ (2013) 152-160. http://dx.doi.org/10.1016/j.solener.2013.01.026. 